\title{
Friction-Stir Welding and Processing
}

\author{
YURI HOVANSKI, ${ }^{1,4}$ JOHN E. CARSLEY, ${ }^{2,5}$ KESTER D. CLARKE, ${ }^{3,6}$ and \\ PAUL E. KRAJEWSKI ${ }^{2,7}$ \\ 1.-Pacific Northwest National Laboratory, Richland, WA, USA. 2.-General Motors Company, \\ Warren, MI, USA. 3.-Los Alamos National Laboratory, Los Alamos, NM, USA. 4.- e-mail: yuri. \\ hovanski@pnnl.gov. 5.—e-mail: john.carsley@gm.com.6.—e-mail: kclarke@lanl.gov. 7.—e-mail: \\ paul.e.krajewski@gm.com
}

With nearly 20 years of international research and collaboration in friction-stir welding (FSW) and processing, industrial applications have spread into nearly every feasible market. Currently, applications exist in aerospace, railway, automotive, personal computers, technology, marine, cutlery, construction, and several other markets. The implementation of FSW has demonstrated diverse opportunities ranging from enabling new materials to reducing the production costs of current welding technologies by enabling condensed packaging solutions for traditional fabrication and assembly. TMS has sponsored focused instruction and communication in this technology area for more than 15 years, with leadership from the Shaping and Forming Committee, which organizes a biannual symposium each odd year at the TMS annual meeting. A focused publication produced from each of these symposia now comprises eight volumes detailing the primary research and development activities in this area over the last two decades. The articles assembled herein focus on both recent developments and technology reviews of several key markets from international experts in this area.

The first three articles document advances in friction-stir processing including additive techniques, application to novel materials, and continued fundamental characterization. This begins with an assessment of friction-stir processing as a technique to form nanocomposites. F. Adel Mehraban, F. Karimzadeh, and M.H. Abbasi demonstrate the ability to disperse nickel oxide powders uniformly throughout an aluminum matrix. Quantitative measurements support their conclusions related to the ability to tailor unique property modifications of base materials with friction-stir processing. This publication along with previously published work shows how material modification via friction-stir

Yuri Hovanski is the guest editor for the Shaping and Forming Committee of the TMS Materials Processing \& Manufacturing Division and the coordinator of the topic "Friction-Stir Welding and Processing" in this issue. processing can be used to selectively modify properties and performance of various materials.

Next, N. Kumar along with a team from the University of North Texas and the University of Tennessee demonstrate novel microstructural modification of high-entropy alloys using frictionstir processing. This unique work presents a viable mechanism for reducing the grain size of high-entropy alloys, and it demonstrates through measurement and characterization that grain boundary strengthening may be an effective mechanism for strengthening high-entropy alloys.

More traditional characterization of a frictionstir-processed precipitation-hardenable aluminum alloy is then presented by N. Nadammal et al. They add to the historical body of research demonstrating that friction-stir processing is an effective method for grain refinement of high-strength aluminum alloys. Their characterization of the microstructure and analysis of the texture development furthers the available information in this area and provides evidence that particle-stimulated nucleation is a dominant mechanism for the nucleation of grains during friction-stir processing.

The next two articles focus on evaluating, controlling, and enabling the effective transfer of heat during and through the implementation of FSW. P. Upadhyay and A.P. Reynolds document both a review of historical literature and the results from novel experimentation to further define the effects of temperature transients caused by variation in thermal boundary conditions during FSW. Their work evaluating variation in the conductivities of backing anvils, clamping, and other boundary conditions significantly aids current and future work in the development and application of FSW. Although this work has been applied to evaluating the influence of heat on precipitation hardening aluminum alloys, clearly the application of the data presented herein has much more broad significance to the overall FSW community. 
This work is augmented by an investigation into the use of FSW to enhance the heat transfer of bimetallic heat exchangers. A.K. Lakshminarayanan presents the work of his team in the production and evaluation of aluminum/copper interfaces. This work includes a comparison of current bolted interfaces with that of novel friction-stir-welded configurations. Each example is evaluated both numerically and experimentally to demonstrate and validate the proposed approach to future implementation and design.

This publication transitions nicely into the final section, which includes two articles documenting the development of FSW to support the transportation industry. The first, by Y. Hovanski et al., documents a multiyear effort developing high-speed friction-stir welding parameters to support highvolume automotive production of aluminum tailorwelded banks. This article presents a combined effort of researchers from General Motors, TWB Company LLC, Alcoa, and the Pacific Northwest National Laboratory. The final article documents the continuing work of A.M. Cantrell and a combined team of researchers from the Boeing Company and the University of Washington. Their work developing effective joining solutions for aerospace titanium alloys includes a significant investigation of FSW. Their article herein presents extensive data on the microstructure and properties of friction-stirwelded Ti-6Al-4V.

The following articles being published under the topic of "Friction-Stir Welding and Processing" provide excellent details and research on the sub- ject. To download any of the papers, follow the URL http://link.springer.com/journal/11837/67/5/page/1 to the table of contents page for the May 2015 issue (vol. 67, no. 5).

- "Development of Surface Nanocomposite Based on Al-Ni-O Ternary System on Al6061 Alloy by Friction-Stir Processing and Evaluation of its Properties,” by F. Adel Mehraban, F. Karimzadeh, and M.H. Abbasi.

- "Friction-Stir Processing of a High-Entropy Alloy $\mathrm{Al}_{0.1} \mathrm{CoCrFeNi}$," by N. Kumar, M. Komarasamy, P. Nelaturu, Z. Tang, P.K. Liaw, and R.S. Mishra

- "Microstructure and Crystallographic Texture Evolution During the Friction-Stir Processing of a Precipitation-Hardenable Aluminum Alloy," by N. Nadammal, S.V. Kailas, J. Szpunar, and S. Suwas.

- "Thermal Management in Friction-Stir Welding of Precipitation-Hardening Aluminum Alloys," by P. Upadhyay and A.P. Reynolds.

- "Thermal Performance Evaluation of FrictionStir-Welded and Bolted Cold Plates with $\mathrm{Al} / \mathrm{Cu}$ Interface," by A.K. Lakshminarayanan, M. Suresh, and M. Sibi Varshan.

- "High-Speed Friction-Stir Welding to Enable Aluminum Tailor-Welded Blanks," by Y. Hovanski, P. Upadyay, J. Carsley, T. Luzanski, B. Carlson, M. Eisenmenger, A. Soulami, D. Marshall, B. Landino, and S. Hartfield-Wunsch.

- "Friction-Stir-Welded Titanium Alloy Ti-6Al-4V: Microstructure, Mechanical, and Fracture Properties," by A.M. Cantrell, D.G. Sanders, M. Ramulu, P. Edwards, and K. Gangwar. 